\title{
Research on Bearing Theory of Squeezed Branch Pile
}

\author{
Hong-wei Ma $\mathbb{D},{ }^{1,2}$ Yi-ying Wu $\mathbb{D}^{1},{ }^{1}$ Yu Tong, ${ }^{1}$ and Xiao-qiang Jiang ${ }^{1}$ \\ ${ }^{1}$ School of Civil Engineering and Architecture, Anhui University of Science and Technology, Huainan 232001, China \\ ${ }^{2}$ State Key Laboratory of Mining Response and Disaster Prevention and Control in Deep Coal Mines, \\ Anhui University of Science and Technology, Huainan, China \\ Correspondence should be addressed to Hong-wei Ma; hw_ma1984@126.com
}

Received 15 November 2020; Revised 27 November 2020; Accepted 8 December 2020; Published 29 December 2020

Academic Editor: Zhi Cheng Tang

Copyright ( 2020 Hong-wei Ma et al. This is an open access article distributed under the Creative Commons Attribution License, which permits unrestricted use, distribution, and reproduction in any medium, provided the original work is properly cited.

\begin{abstract}
Based on the shear displacement method, theoretical research on the load transfer relation of squeezed branch pile is established. In combination with the nonlinear relation of the interaction between piles and soil, the hyperbolic function is used to describe the pile tip, pile skin, and branch. The theoretical method of the load transfer is improved, and the expression of the load transfer coefficient of these three parts is given. Finally, the applicability of the theoretical method is verified by the model test of homogeneous soil and the field test of stratified soil. The verification results show that the theoretical calculation method of the squeezed branch single-pile bearing capacity based on the shear displacement method can better calculate the ultimate load in practical engineering applications.
\end{abstract}

\section{Introduction}

The squeezed branch pile is a kind of friction-end bearing pile, which is formed by squeezing into an expanded body at a specific position based on the cast-in-place pile. Thanks to the function of the expanded body, the load-bearing system of branch resistance-shaft resistance-tip resistance is helpful to realize the high bearing capacity and low settlement. At present, related applied research and engineering practices have been carried out in many engineering fields, such as large-scale factory projects and infrastructure construction in clay soil areas (Yin et al. [1] and Xiao et al. [2]).

With the development of engineering technology, the research on bearing characteristics of squeezed branch piles has gradually deepened. Yang et al. [3] obtained the bearing characteristics of high bearing capacity and low settlement through comparative tests of large diameter piles on the same site. Li et al. [4] analyzed the working mechanism of squeezed branch piles in actual projects and found that the expanded body has a high contribution to the bearing capacity of the pile foundation. Zhang and Wang [5] verified the aforementioned bearing characteristics by field comparison tests. It is also proposed that the reasonable setting of the expanded body and the selection of the diameter of the branch have a significant impact on the bearing capacity, Cui and Wang [6], Zhang et al. [7], and Liu et al. [8] verified the excellent application prospect of the squeezed branch pile under different site conditions through the field static load test. The aforementioned studies can prove the good site adaptability of squeezed branch piles. It is of great significance to carry out corresponding theoretical research and practice based on the bearing characteristics of the squeezed branch pile.

Therefore, many scholars have carried out studies mainly on the bearing mechanism and the load-settlement relationship of squeezed branch piles. Liang et al. [9] analyzed the influence of the pile-soil interaction state on the bearing capacity of the pile and proposed a variable section calculation method of pile load-settlement characteristics. Wu et al. [10] proposed a settlement calculation method for squeezed multibranch piles based on the layered summation method. Ju et al. [11] analyzed the pile-soil interaction under load and proposed a revised reference for the design formula of bearing capacity in the code. Gao and Zhu [12] analyzed the characteristics of the load-settlement curve of the squeezed branch piles in actual projects, predicted the ultimate bearing capacity of the squeezed branch piles through the hyperbolic model, and obtained theory results closer to 
the measured values. Jiang et al. [13] improved the accuracy of bearing capacity calculation by using the power functionhyperbolic combination model. Other scholars have carried out theoretical research on the bearing characteristics of squeezed branch piles. Liu et al. [14] established the relationship between the bearing capacity and settlement of multistage enlarged piles based on the load transfer law of the pile foundation from top to bottom. The calculation formula is obtained, and the calculation result is more consistent with the measured values. Li et al. [15] combined the load-bearing system of branch resistance-shaft resistance-tip resistance and carried out a nonlinear simplified analysis of the load-settlement characteristics of squeezed branch piles through a segmented displacement coordinated iteration algorithm.

The expanded branch can bear more loads, and the damage of the squeeze branch pile is mainly due to the shear failure of the soil under the branch or the failure of the soil at the pile end, which is different from the conventional bearing capacity design method. The side resistance of the squeezed branch pile is limited by the branch resistance, and the pile foundation will completely fail after the expanded body is damaged. Therefore, this paper establishes the loadsettlement calculation theory of squeezed branch pile based on the shear displacement method. Combined with the model test of homogeneous soil and the field test of stratified soil, the calculation theory was verified, respectively. According to the verification results, we can analyze the stress mechanism of the squeezed branch pile.

\section{Theoretical Analysis}

2.1. Bearing Theory of Pile Foundation by the Shear Displacement Method. As shown in Figure 1, the bearing theory of the shear displacement method proposes that the soil around the pile undergoes shear deformation with the settlement of the pile, and the shear deformation is transferred from the radius $r_{0}$ of the pile to the influence radius $r_{m}$, and equation (1) represents the transfer relationship of shear stress $\tau(z)$ in the radial direction, and equation (2) represents the elastic relationship between shear stress $\tau(z)$ and shear strain in the soil at the side of the pile:

$$
\begin{gathered}
\tau(z)=\tau_{0}(z) \frac{r_{0}}{r_{m}}, \\
\tau(z)=G_{s} \frac{\mathrm{d} w(r)}{\mathrm{d} r} .
\end{gathered}
$$

As shown in equations (1) and (2), Randolph and Wroth [16] put forward the influence radius $r_{m}=2.5 H \rho_{m}$ $(1-\nu) ; H$ is the depth of the calculated section. $\rho_{m}$ is the correction coefficient of finite-depth soil; $\rho_{m}$ is taken as 1 in the homogeneous soil layer; $\nu$ is Poisson's ratio of the soil at the side of the pile; $\tau_{0}(z)$ is the shear force of the pile-soil contact surface at depth $z$; and $G_{s}$ is the shear modulus of the soil.

Combining equations (1) and (2), the displacement of the soil at the side of the pile is obtained by integral:

$$
\begin{cases}w(r)=\frac{\tau_{0}(z) r_{0}}{G_{s}} \ln \frac{r_{m}}{r}, & r_{0} \leq r \leq r_{m}, \\ w(r)=0, & r \geq r_{m} .\end{cases}
$$

Under the load state, equation (4) takes an element of a single pile for force balance analysis, and the relationship between the pile side displacement $w\left(r_{0}\right)$ and axial force is shown in equation (5):

$$
\begin{aligned}
& \frac{\mathrm{d} F(z)}{\mathrm{d} z}=2 \pi r_{0} \tau_{0}(z), \\
& \frac{\partial w\left(r_{0}\right)}{\partial z}=\frac{F(z)}{\pi r_{0}^{2} E_{p}} .
\end{aligned}
$$

As shown in equations (4) and (5), $F(z)$ is the axial force of the pile section at depth $z ; E_{p}$ is the elastic modulus of the pile.

At the same depth $z$, the displacement of the soil at the side of the pile is equal to the pile side displacement. By combining equations (3)-(5), the displacement balance equation can be established as follows:

$$
\frac{\partial^{2} w\left(r_{0}\right)}{\partial z^{2}}-\frac{2 G_{s}}{r_{0}^{2} E_{p} \ln \left(r_{m} / r_{0}\right)} w\left(r_{0}\right)=0 .
$$

The general solution of equation (6) is

$$
w=m_{1} e^{\alpha z}+m_{2} e^{-\alpha z} .
$$

As shown in equation (7), $m_{1}$ and $m_{2}$ are undetermined constants; the calculation method for parameter $\alpha$ is shown as follows:

$$
\alpha=\left(2 G_{s} \ln \left(r_{m} / r_{0}\right)^{1 / 2} r_{0}^{2} E_{p}\right)^{1 / 2} .
$$

\subsection{Bearing Theoretical Calculation Model of Squeezed Branch} Pile. Seed and Reese [17] proposed the load-settlement hyperbolic relationship at the end of the pile, and the relationship between the pile tip resistance $P_{b}$ and the settlement $s_{b}$ is shown as follows:

$$
P_{b}=A \frac{s_{b}}{a_{s}+b_{s} s_{b}} .
$$

In equation (9), the cross-sectional area of the straight hole section $A=\pi d^{2} / 4, d$ is the pile diameter and $a_{s}$ and $b_{s}$ are the transferred parameters of the pile tip resistance.

As shown in Figure 2, the length of the pile shaft under the $n$th expanded body is $l_{n}$. Assuming that the pile tip resistance is $P_{b}$ and pile tip settlement is $s_{b}$, and combining the bearing theory of the shear displacement method, the displacement of the section under the $n$th expanded body can be obtained as

$$
s_{n}=\cosh \left(\alpha l_{n}\right) s_{b}+\frac{\sinh \left(\alpha l_{n}\right)}{\alpha A E_{p}} P_{b} .
$$




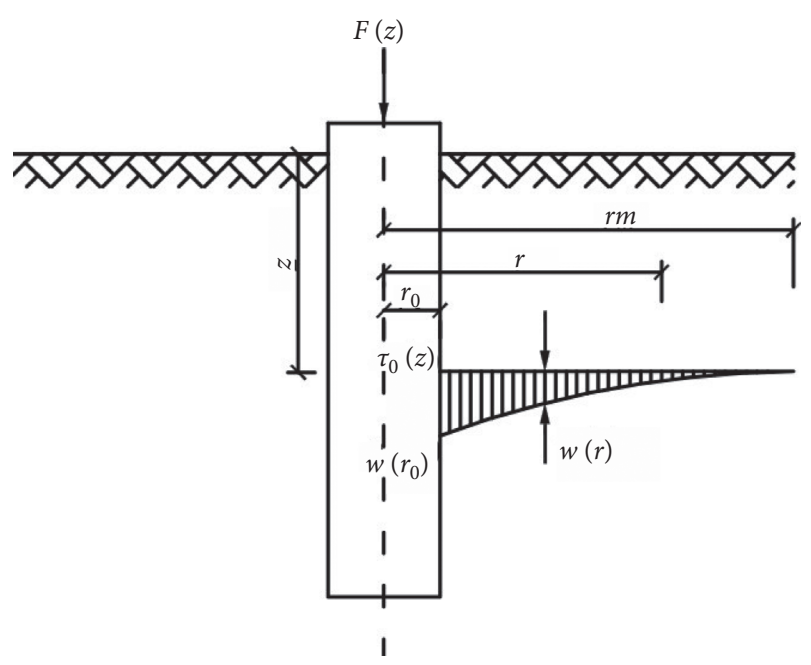

Figure 1: Pile-soil shear displacement model.

In equation (10), $L$ is the pile length and $E_{p}$ is the elastic modulus of the pile shaft.

Assuming that the shaft resistance $f_{n}$ of the pile shaft varies linearly along the pile body, $f_{n}$ can be shown as

$$
f_{n}=\pi d l_{n} \frac{\tau_{n}+\tau_{b}}{2} .
$$

In equation (11), $\tau_{n}$ is the shear stress at the section under the $n$th expanded body and $\tau_{b}$ is the shear stress at the pile end.

The shear stress and settlement satisfy the hyperbolic function relationship:

$$
\begin{gathered}
\tau_{n}=\frac{s_{n}}{a_{f n}+b_{f n} s_{n}}, \\
\tau_{b}=\frac{s_{b}}{a_{f b}+b_{f b} s_{b}} .
\end{gathered}
$$

In the formula, $a_{f n}$ and $b_{f n}$ are the transfer parameters of the shear force under the $n$th expanded body; $a_{f b}$ and $b_{f b}$ are the transfer parameters of the shear force at the pile end.

For nonrigid piles, the pile would be compressed when the pile is loaded. Assuming that the load $\mathrm{d} F$ acts on the microelement $\mathrm{d} z$ of the pile, the static balance relationship of the microelement segment is satisfied as follows:

$$
\begin{aligned}
\mathrm{d} F & =\pi d \frac{s}{a_{f b}+b_{f b} s} \mathrm{~d} z, \\
\mathrm{~d} s & =\frac{F}{E_{p} A} \mathrm{~d} z,
\end{aligned}
$$

where $s$ is the settlement of the microelement section relative to the reference section and $F$ is the axial force difference of upper and lower sections of the microelement section.

From equations (14) and (15), the differential equation for the axial force transfer of the pile shaft is

$$
F \mathrm{~d} F=\pi \mathrm{d} E_{P} A \frac{s}{a_{f b}+b_{f b} s} \mathrm{~d} s .
$$

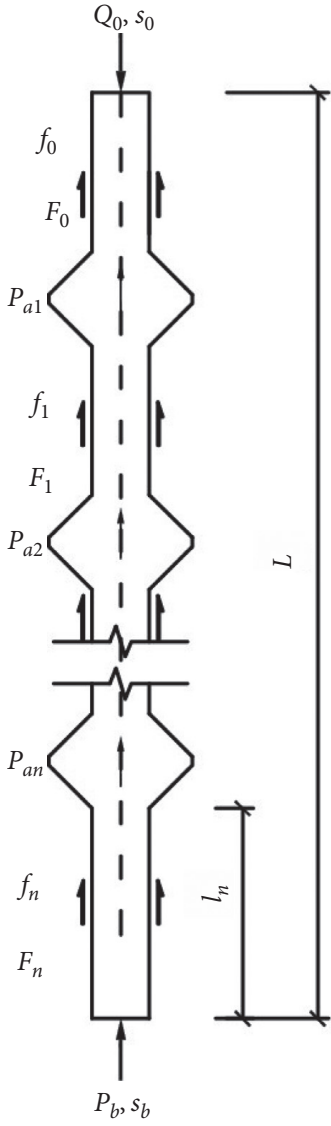

FIgURE 2: Calculation model of the squeezed branch pile.

Combining the initial conditions $F=0$ and $s=0$ to integrate equation (16), we get

$$
F=\frac{\sqrt{2 \pi \mathrm{d} E_{P} A}}{b_{f b}} \sqrt{b_{f b} s-a_{f b} \ln \left(1+\frac{b_{f b}}{a_{f b}} s\right) .}
$$

From the results of the shear displacement of the pile shaft $l_{n}$, it can be seen that the compression of the pile shaft $l_{n}$ is

$$
s_{c}^{n}=s_{n}-s_{b} .
$$

Therefore, the additional axial force required to provide compression of the pile shaft $l_{n}$ is

$$
F_{n}=\frac{\sqrt{2 \pi \mathrm{d} E_{P} A}}{b_{f b}} \sqrt{b_{f b} s_{c}^{n}-a_{f b} \ln \left(1+\frac{b_{f b}}{a_{f b}} s_{c}^{n}\right)} .
$$

Since the rigidity of the expanded body is much greater than the pile shaft, it is assumed that the settlement of each section of the expanded body is equal under the same load. The load-bearing method of the expanded body can be simplified, as the branch resistance acts vertically on the expanded ring area. Same as pile end, the relationship between the branch resistance $P_{a n}$ and the settlement $s_{n}$ of the $n$th expanded body is shown as follows: 


$$
P_{a n}=A_{p n} \frac{s_{n}}{a_{p n}+b_{p n} s_{a n}} .
$$

In equation (20), $P_{a}$ represents the branch resistance, $A_{p}$ represents the expanded ring area, and $s_{n}$ represents the settlement of the $n$th expanded body. The annular crosssectional area of the expanded body $A_{p n}=\pi\left(D_{n}{ }^{2}-d^{2}\right) / 4, D_{n}$ is the diameter of the $n$th expanded body, and $a_{p n}$ and $b_{p n}$ are the transferred parameters of the branch resistance of the $n$th expanded body.

Regarding the $n$th expanded body and the pile shaft under the body as an expanded unit, the axial force transmitted to the top of the unit is $R_{n}$ :

$$
R_{n}=P_{a n}+P_{b}+f_{n}+F_{n} .
$$

For the squeezed branch pile with $n$ expanded units, the calculation process of the squeezed branch pile is shown in Figure 3.

When any set of the pile tip settlement $s_{b}$ is given, the corresponding pile top load and pile top settlement can be obtained by the above calculation. Taking any pile top load $Q$ and the settlement $s, Q_{p}$ and $Q_{q}$ can be determined, where $Q_{p}=10 / 12 Q, Q_{q}=11 / 12 Q, s_{p}$ is the corresponding settlement of the pile top $Q_{p}$, and $s_{q}$ is the corresponding settlement of the pile top $Q_{q}$, where $\Delta s_{1}=s_{q}-s_{p}, \Delta s_{2}=s-s_{q}$, any $Q$ is selected. When $\Delta s_{2}>2 \Delta s_{1}$, the ultimate bearing capacity of the pile can be determined to be $11 / 12 Q$.

\subsection{Calculation Parameters}

2.3.1. $a_{s}$ and $b_{s}$. Randolph and Wroth [18] studied the nonlinear relationship between the pile tip resistance and pile tip settlement:

$$
s_{b}=\frac{P_{b}\left(1-v_{b}\right)}{2 G_{b} d} .
$$

In the formula, $G_{b}$ is the shear modulus of the pile-end soil and $v_{b}$ is Poisson's ratio of the pile-end soil.

Therefore,

$$
a_{s}=\frac{\left(1-v_{b}\right) \pi d}{8 G_{b}}
$$

Janbu [19] gives the ultimate tip resistance $P_{b u}$ of straight hole piles:

$$
\begin{aligned}
P_{b u} & =\left(c_{b} N_{c}+q_{b} N_{q}\right) A, \\
b_{s} & =\frac{1}{\left(c_{b} N_{c}+q_{b} N_{q}\right)} .
\end{aligned}
$$

In the formula, $c_{b}$ is the cohesive force of the pile tip soil, $q_{b}$ is the average effective compressive stress on the side of the pile tip plane, and $N_{c}$ and $N_{q}$ are the bearing capacity coefficients of the pile. The calculation is shown in the following formula, where $\phi$ is the angle of the failure surface of the pile tip under the ultimate load and the range from soft clay to compact sand is $60^{\circ}$ to $105^{\circ}$, where $\gamma$ is the soil gravity on the side of the pile and $\varphi$ is the effective internal friction angle of the soil.

$$
\begin{aligned}
& N_{c}=\left(N_{q}-1\right) \cot \varphi, \\
& N_{q}=\left(\tan \varphi+\sqrt{1+\tan ^{2} \varphi}\right)^{2} e^{2 \phi \tan \varphi} .
\end{aligned}
$$

2.3.2. $a_{f}$ and $b_{f}$. The relationship between the shear displacement of the pile side soil and the shear stiffness is given by equation (3). Let $r=r_{0}$, then the shaft resistance transfer parameter $a_{f}$ can be shown as

$$
a_{f}=\frac{d}{2 G_{s}} \ln \frac{2 r_{m}}{d}
$$

The shear strength of the pile-soil interface can be shown as

$$
\tau_{f}=k \sigma_{v} \tan \delta
$$

Therefore,

$$
b_{f}=\frac{R_{f}}{k \sigma_{v} \tan \delta} .
$$

In the formula, $R_{f}$ is the failure ratio, which can be taken as $0.80 \sim 0.95$ and $k$ is the horizontal earth pressure coefficient, which can be taken according to Table 1 . In Table $1, k_{0}$ is the static earth pressure coefficient, $k_{0}=1-\sin \varphi, \sigma_{v}$ is the vertical stress of the soil at the calculated height and $\delta$ is the friction angle of the pile-soil interface.

\section{Determination of Disk Resistance Function Based on Model Test}

\subsection{Test Sand and Model Pile}

3.1.1. Preparation of Model Piles. As shown in Figure 4, the model pile is made of aluminum alloy, and the pile end and pile head are sealed with the same material. The pile diameter $d=20 \mathrm{~mm}$, the depth of the pile body into the soil $L=500 \mathrm{~mm}$ in the test, the exposed pile head is $50 \mathrm{~mm}$, and the length-to-diameter ratio is $25: 1$. The inclination angle of the branch surface $\alpha=45^{\circ}$ and a $\varphi 20$ circular hole is left inside. The dimensions are shown in Figure 1(b). According to the different diameters of the expanded body, the piles were divided into 5 groups. The parameters of each group are shown in Table 2.

3.1.2. Preparation of Test Sand. Before the test, the natural sand was cleaned and dried first, and then the test sand was screened with a $2.45 \mathrm{~mm}$ aperture fine sieve to remove larger particles and impurities. After fixing the position of the model pile with the self-made device, the test sand was filled in six layers, and the filling mass of each layer was controlled to $80 \mathrm{~kg}$. A small vibratory trowel with a vibration frequency of 2840 times/min was used for tamping for $1 \mathrm{~min}$. The compaction state measured by the light penetrometer was of 


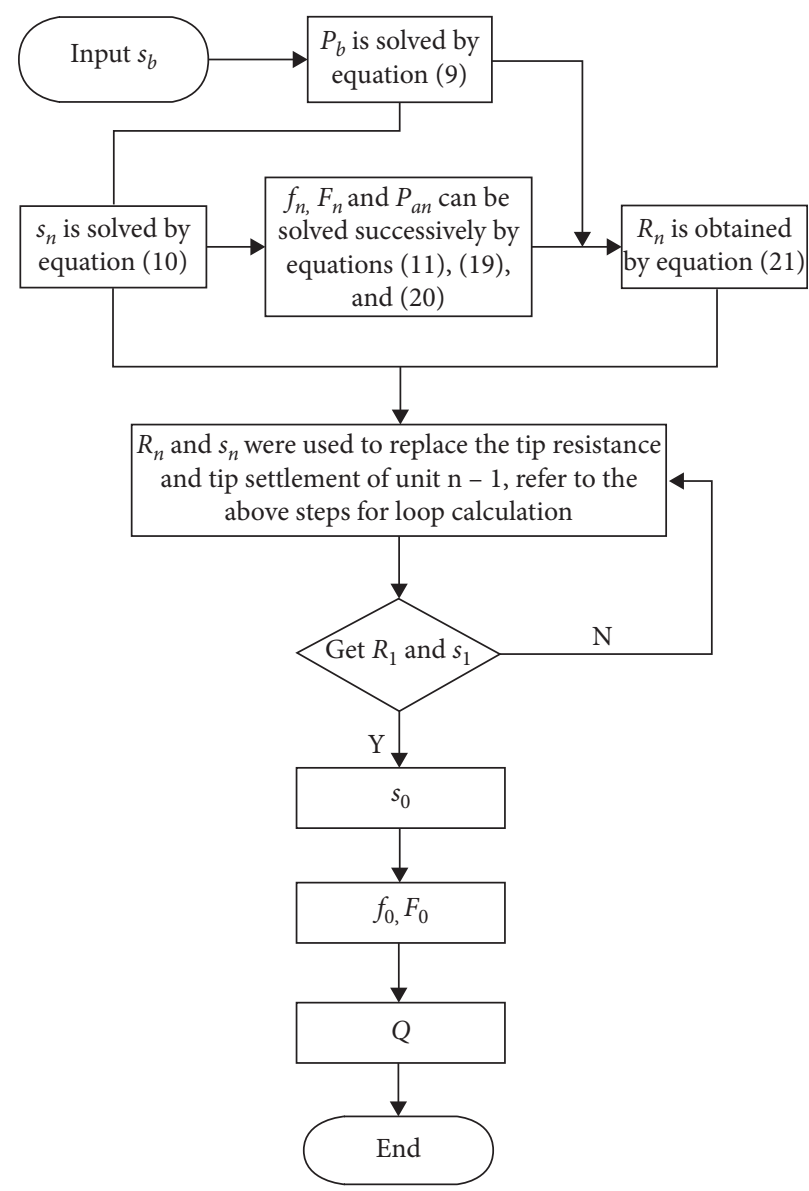

FIGURE 3: The calculation of the bearing capacity of the squeezed branch pile.

TABle 1: Suggested value of the lateral earth pressure coefficient $k$.

\begin{tabular}{lccc}
\hline Data provider & Working conditions & $k$ \\
\hline Kulhawy [20] & Steel pipe piles, concrete piles or H-shaped steel piles with a smooth surface, and a small settlement & $(0.7 \sim 1.2)$ & $k_{0}$ \\
Yang [21] & Driven steel piles in alluvial deposit or fully weathered granite & $(1.2 \sim 1.5)$ & $k_{0}$
\end{tabular}

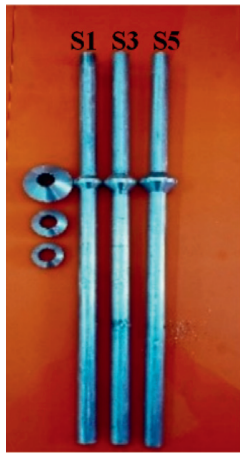

(a)

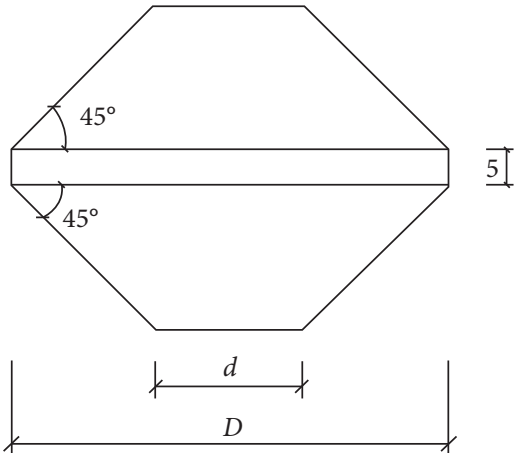

(b)

Figure 4: The model of the squeezed branch pile. (a) Model pile. (b) Branch bearing. 
TABLE 2: The parameters of the model pile.

\begin{tabular}{lcccc}
\hline Group & $D(\mathrm{~mm})$ & $h(\mathrm{~mm})$ & $l_{1}(\mathrm{~mm})$ & \\
\hline S1 & 40 & 25 & 137.5 & \\
S2 & 45 & 30 & 135.0 & 337.5 \\
S3 & 50 & 35 & 132.5 & 335.0 \\
S4 & 55 & 40 & 130.0 & 332.5 \\
S5 & 60 & 45 & 127.5 & 330.0 \\
\hline
\end{tabular}

medium density and was kept still for 12 hours after the landfill is completed.

\subsection{Test Loading}

3.2.1. Test Loading Device. The loading device is shown in Figure 5.

The clearance size of the model box is $0.8 \mathrm{~mm} \times 0.6 \mathrm{~m} \times 0.58 \mathrm{~m}(L \times W \times H)$, which meets the test error control requirements. The sidewall of the model box is made of a combination of $12 \mathrm{~mm}$ thick plexiglass plate and using an $8 \mathrm{~mm}$ thick steel bar hoop for reinforcement, and the bottom is sealed with a $12 \mathrm{~mm}$ thick plexiglass plate. During the test, the maximum deformation of the sidewall of the model box was measured to be less than $0.1 \mathrm{~mm}$, and it indicates that the stiffness of the model box did not affect the test results.

The test loading device adopts lever-type loading, and a balance system is designed in the loading system to eliminate the weight of the steel beam and the loading plate. To ensure that the center of the pile is under load, a solid alloy steel ball is used to transmit the force at the position of the pile head.

3.2.2. Loading Steps and Limit State Determination. The load of each stage of the test is $0.2 \mathrm{kN}$. After each stage of loading is completed, the settlement of the model pile is observed every 5 minutes. If the difference between the two adjacent observations is less than $0.01 \mathrm{~mm}$, it means that the stable state is reached and the next level of loading begins. If the corresponding settlement of a certain level of the load exceeds 2 times of the previous level, it means that the load limit state has been reached. We determine the ultimate state of the load from two aspects. One is that the settlement of this stage is more than twice that of the previous stage. The other is that settlement dose not reach a stable state within 1.5 hours. It is determined that the total load to the upper level is the ultimate bearing capacity of the pile.

3.3. The Load Transfer Coefficients of the Branch Resistance. The deflections $\chi(\beta)$ of the branch end load were determined from six groups of indoor model experiments on a small scale. The resistance strain gauges on both sides of the pile body were measured, and the vertical displacement of the pile top was monitored by using a dial indicator.

The layout plan of the axial measuring point is shown in Figure 6.

Determination of resistance load transfer coefficients $a_{p}$ and $b_{p}$ at the branch:
The load-bearing method at the expanded body is same as the pile end, but it is only affected by the diameter of ball bearing and the interaction between ball bearing and the soil. Therefore, assuming that the branch resistance is equivalently simplified to the tip resistance form, which is shown as follows:

$$
\begin{aligned}
& P_{a}=A\left(\beta^{2}-1\right) \frac{s_{a}}{a_{p}+b_{p} s_{a}}=\frac{R_{b}}{\chi(\beta)}, \\
& R_{b}=A \frac{s_{a}}{a_{s p}+b_{s p} s_{a}} .
\end{aligned}
$$

In the formula, $R_{b}$ is the equivalent tip resistance, $a_{s p}$ and $b_{s p}$ are the transfer parameters of ball bearing, the calculation refers to $a_{s}$ and $b_{s}, \chi(\beta)$ is the correct function of the branch resistance, and $\beta$ is the ratio of the branch bearing diameter to the pile diameter.

From equations (31) and (32), the transfer coefficients $a_{p}$ and $b_{p}$ of the expanded body can be shown as follows:

$$
\begin{aligned}
& a_{p}=\left(\beta^{2}-1\right) \chi(\beta) a_{s p} \\
& b_{p}=\left(\beta^{2}-1\right) \chi(\beta) b_{s p} .
\end{aligned}
$$

Equation (31) can be transformed into

$$
\frac{s_{a}}{P_{a}}=\frac{a_{p}}{A\left(\beta^{2}-1\right)}+\frac{b_{p}}{A\left(\beta^{2}-1\right)} s_{a} .
$$

Let $y=s_{a} / P_{a}$ and $x=s_{a}$, then $y=k x+c$

$$
\begin{aligned}
& k=\frac{b_{p}}{A\left(\beta^{2}-1\right)}, \\
& c=\frac{a_{p}}{A\left(\beta^{2}-1\right)} .
\end{aligned}
$$

According to the principle of least squares, it can be obtained

$$
\begin{aligned}
& k=\frac{\sum_{i=1}^{n} x_{i} y_{i}-n \overline{x y}}{\sum_{i=1}^{n} x_{i}^{2}-n \bar{x}^{2}}=\frac{l_{x y}}{l_{x x}}, \\
& c=\bar{y}-k \bar{x}, \\
& \gamma=\frac{l_{x y}}{\sqrt{l_{x x}} \sqrt{l_{y y}}},
\end{aligned}
$$

where, 


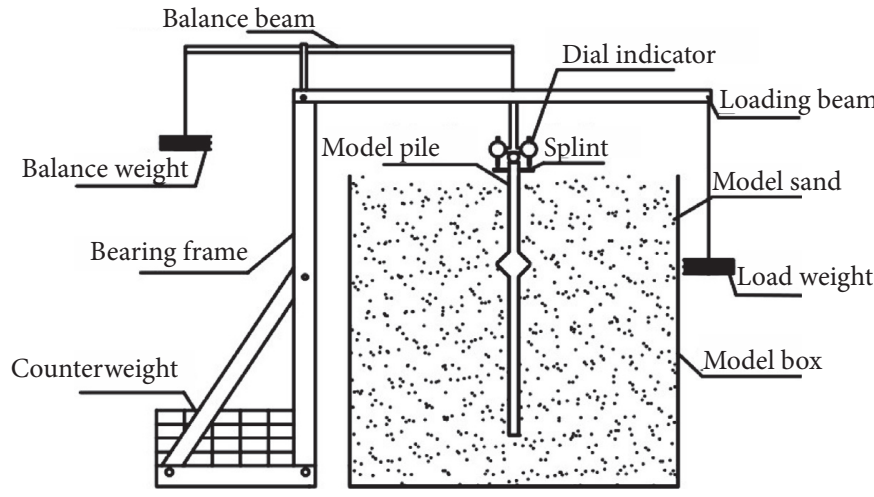

(a)

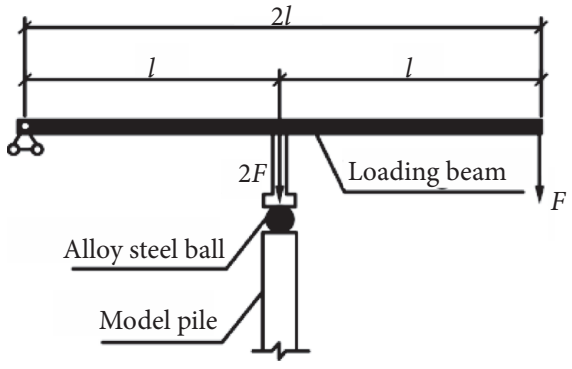

(b)

FIgURE 5: Loading device: (a) schematic diagram of loading device and (b) details of loading points.

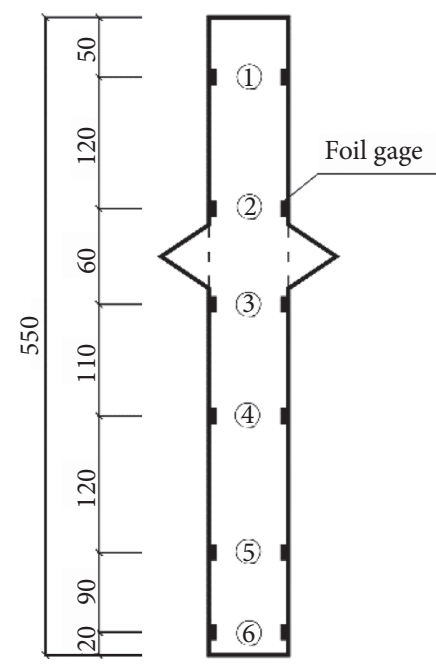

Figure 6: The layout plan of the axial measuring point.

$$
\begin{gathered}
\bar{x}=\frac{1}{n} \sum_{i=1}^{n} x_{i}, \\
\bar{y}=\frac{1}{n} \sum_{i=1}^{n} y_{i}, \\
l_{y y}=\sum_{i=1}^{n} y_{i}^{2}-n \bar{y}^{2} .
\end{gathered}
$$

Combining equations (34) and (38), the function $\chi(\beta)$ is simplified as

$$
\chi(\beta)=\frac{k A}{b_{s p}} .
$$

The function $\chi(\beta)$ is determined according to the axial force data of the pile of 6 groups of model pile tests, and the correction function value of the branch resistance is shown in Table 3.

According to the static load test results, multiple groups of $P_{a}$ and $s_{a}$ in the elastic-plastic state are determined. The parameters $k$ and $c$ are obtained according to the least square method. The correction value $\chi(\beta)$ of each diameter is obtained by data fitting and shown in Table 3. The obtained empirical formula of the branch resistance correction for each diameter is

$$
\chi(\beta)=0.36 \beta^{2}-2.36 \beta+4.20 .
$$

According to the above calculation and derivation, the transfer parameters of the pile tip resistance, shaft resistance, and branch resistance can be determined.

\section{Test Verification and Analysis}

4.1. Theoretical Verification and Comparative Analysis of OnSite Large-Scale Test. According to Tang [22], field largescale test data, the length of the No. 1 pile is $2 \mathrm{~m}$, the pile diameter $d=150 \mathrm{~mm}$, the diameter of the bell bearing $D=300 \mathrm{~mm}$, and the bell bearing is set at $1 \mathrm{~m}$ below the top of the pile. The bell bearing is set in dense clay, and the pile tip is in a sandy silt layer. Poisson's ratio of the clay around the pile is 0.25 , the sandy silt of the pile tip is 0.3 , and the failure angle of the pile tip is $95^{\circ}$, and the physical parameters of the remaining soil layers are shown in Table 4. According to the measured data, and combining the theoretical method of this paper, the comparison of load-settlement between the theoretical curve and the measured curve of the No. 1 pile is shown in Figure 7, and the theoretical and measured values are shown in Table 5.

It can be seen from Figure 6 that the theoretical curve obtained by the calculation method in this paper has a relatively close change trend with the field measured curve. Since the soil under the expanded body has reached an elastoplastic state after rolling at the initial stage of loading, the pile top load increases approximately linearly with the pile top settlement. At the initial stage of loading, the theoretical calculation takes the influence of the elastic state of the pile and soil into account and obtained a slow-change theoretical curve that is more consistent with the actual projects. It can be seen from Table 5 that with the increase of the pile top loading, the relative error between the theoretical value and measured value gradually decreases. In the middle and late loading period, although the theoretical curve and measured value do not completely overlap, they can 
TABLE 3: Correction function value of branch resistance.

\begin{tabular}{ccccccccccc}
\hline \multirow{2}{*}{ No. } & \multicolumn{2}{c}{$\mathrm{S} 1$} & \multicolumn{2}{c}{$\mathrm{S} 3$} & \multicolumn{2}{c}{$\mathrm{S} 4$} & \multicolumn{2}{c}{$\mathrm{S} 5$} \\
& $P_{a}(\mathrm{~N})$ & $s_{a}(\mathrm{~mm})$ & $P_{a}(\mathrm{~N})$ & $s_{a}(\mathrm{~mm})$ & $P_{a}(\mathrm{~N})$ & $s_{a}(\mathrm{~mm})$ & $P_{a}(\mathrm{~N})$ & $s_{a}(\mathrm{~mm})$ & $P_{a}(\mathrm{~N})$ & $s_{a}(\mathrm{~mm})$ \\
\hline 478 & 1.80 & 714 & 2.61 & 550 & 1.50 & 585 & 1.38 & 631 \\
\\
630 & 3.15 & 895 & 4.32 & 746 & 2.42 & 797 & 2.13 & 862 \\
774 & 5.77 & 985 & 5.63 & 946 & 3.82 & 1017 & 3.22 & 1101 & 2.82 \\
& 884 & 8.20 & 1075 & 7.54 & 1047 & 4.83 & 1129 & 3.93 & 1224 & 3.13 \\
& & 1165 & 10.64 & 1148 & 6.15 & 1243 & 4.83 & 1349 \\
\hline
\end{tabular}

TABLE 4: Basic physical and mechanical parameters of the ground at the test site.

\begin{tabular}{lcccccccc}
\hline No. & $\begin{array}{c}\text { Soil } \\
\text { layer }\end{array}$ & $H(\mathrm{~m})$ & $h(\mathrm{~m})$ & $E_{s}(\mathrm{MPa})$ & $\begin{array}{c}\rho \\
\left(\mathrm{g} / \mathrm{cm}^{3}\right)\end{array}$ & $e$ & $c(\mathrm{kPa})$ & $\varphi\left({ }^{\circ}\right)$ \\
\hline 1 & $\begin{array}{c}\text { Clay } \\
1\end{array}$ & 1.7 & $0 \sim 1.6$ & 9.1 & 1.81 & 0.64 & 13.9 & 23 \\
2 & $\begin{array}{c}\text { Sandy } \\
\text { silt }\end{array}$ & 1.0 & $1.6 \sim 1.8$ & 39 & 2.1 & - & 0 & 25 \\
\hline
\end{tabular}

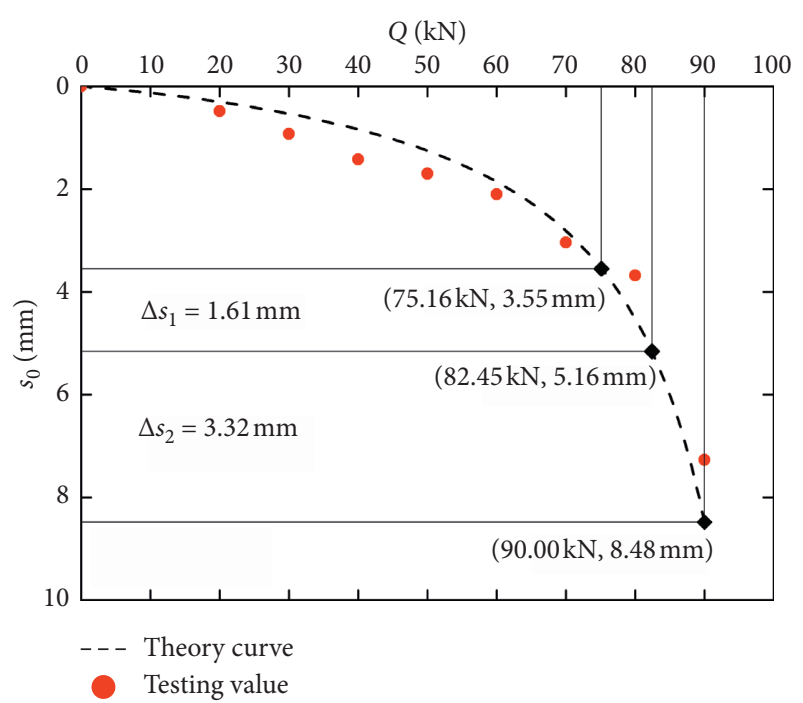

FIgure 7: Comparison of Q-s curves in the field test.

maintain parallel growth. The relative error can be controlled within 5\%. Under the loading limit state, the ultimate calculated bearing capacity of the pile by the theory is $82.45 \mathrm{kN}$, which is in good agreement with the measured value.

\subsection{Theoretical Verification and Comparative Analysis of Indoor Test}

4.2.1. Load-Settlement Relationship. The same pile tip settlement is given as the small-scale test. According to the theoretical calculation results, the five groups of pile top load-settlement curves with different diameters are shown in Figure 8. Under the same pile top settlement $s_{0}$, the error analysis of the theoretical value and measured value of the pile top load is shown in Figure 9.

As shown in Figure 8, at the initial stage of loading, the theory load of the pile top is lower than the measured value.
When the load on the pile top is small, the pile foundation and the soil at the side of the pile are in an elastic state, and the bearing characteristics of the squeezed branch piles are affected by the pile-soil interaction. The theoretical value and measured value are easy to deviate. With the increase of the load on the pile top, the soil around the pile gradually reaches an elastic-plastic state. By the middle and late loading period, the measured curve and theoretical curve have approximately overlapped. As shown in Figure 9, the influence of the pile-soil interaction state on the bearing capacity of the squeezed branch pile is more important at the beginning. As $s_{0}$ increases, the relative error between the theoretical value and measured value gradually decreases. When $s_{0}$ exceeds $2 \mathrm{~mm}$, the error of the pile top load under each diameter is less than $5 \%$, and in the middle and late loading period, the theory curves and measured curves maintain a relatively consistent trend, and the errors of the two measured values are mostly close to 0 .

The error analysis of the ultimate bearing capacity of each group obtained by theoretical calculation is shown in Table 6. As shown in Table 6, the theoretical ultimate bearing capacity under the load limit state is in good agreement with the actual measured value. The relative error of the ultimate bearing capacity under different diameters is less than $2 \%$, which can be controlled within a reasonable range. Therefore, the ultimate bearing capacity of squeezed branch piles can be predicted based on the actual working conditions and the method described in this article.

4.2.2. Bearing Strength Analysis. Taking the $\mathrm{S} 1(D=40 \mathrm{~mm})$, S3 $(D=50 \mathrm{~mm})$, and S5 $(D=60 \mathrm{~mm})$ groups of squeezed branch piles as examples, the contribution of each resistance under the same $s_{0}$ is shown in Figure 10.

As shown in Figure 10, the theoretical resistance contribution rate is closer to the measured contribution rate under the same settlement. As the branch diameter increases, the coincidence between the measured resistance contribution rate and theoretical contribution rate gradually increases. At the initial stage of loading, the measured resistance contribution rate is in low agreement with the theory result. The contribution rate of each resistance value obtained from the theoretical calculation maintains regular increase or decrease without sudden change. Under the test conditions, the soil at the pile end had been tamped and reached an elastoplastic state, and the contribution rate of the measured resistance value is easily biased due to the influence of the test error. With the increase of top load, when reaching the middle and late loading period, the 
TABLE 5: Comparison of the theoretical and measured value.

\begin{tabular}{|c|c|c|c|c|c|c|c|c|}
\hline$s_{0}(\mathrm{~mm})$ & 0.48 & 0.92 & 1.42 & 1.70 & 2.10 & 3.04 & 3.68 & 7.27 \\
\hline Measured value & 20.00 & 30.00 & 40.00 & 50.00 & 60.00 & 70.00 & 80.00 & 90.00 \\
\hline Theoretical value & 27.91 & 42.24 & 53.13 & 57.72 & 63.03 & 71.79 & 75.92 & 87.91 \\
\hline Relative error (\%) & 39.54 & 40.81 & 32.84 & 15.45 & 5.05 & 2.56 & -5.09 & -2.32 \\
\hline
\end{tabular}

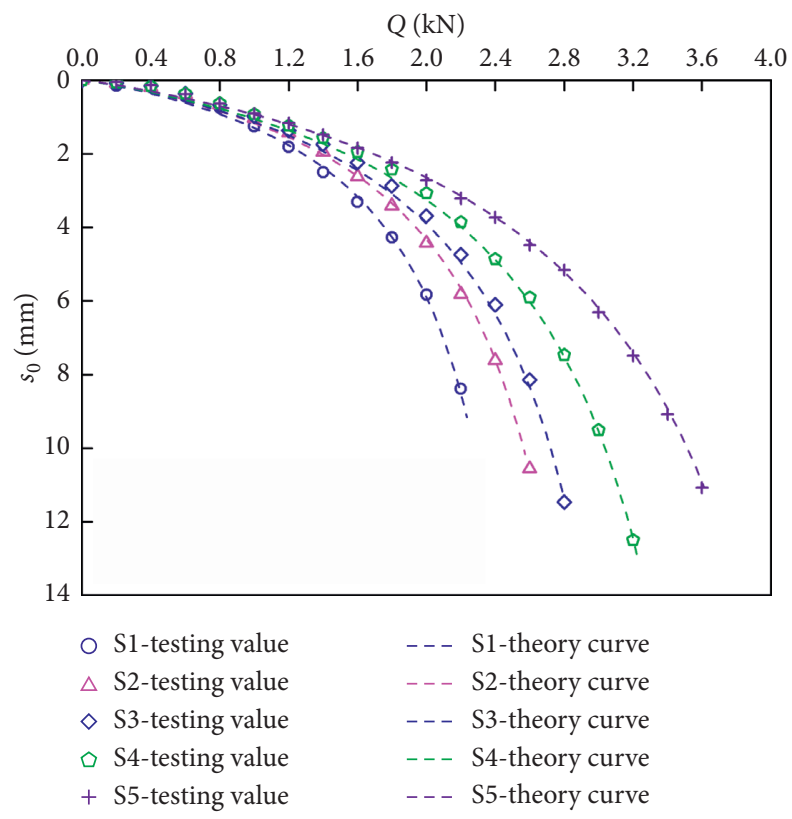

Figure 8: Comparison of $Q-s$ curves between testing value and theory result.

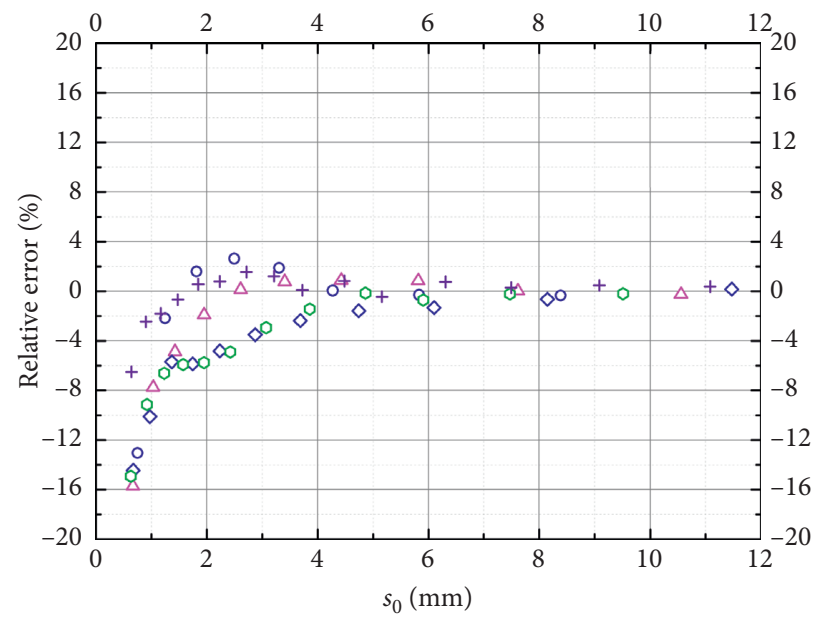
O S1
$\checkmark \mathrm{S} 4$
$\triangle \mathrm{S} 2$
+ S5
$\diamond \mathrm{S} 3$

Figure 9: Error analysis of the theoretical and measured value.

contribution rate of the measured resistance value and theoretical resistance value shows a coincidence or parallel increase. Based on the relationship between the resistance contribution rate of each group, the bearing strength of each part of the squeezed branch pile can be reasonably predicted by the theory method in actual projects. 
TABLE 6: Error analysis of the ultimate bearing capacity.

\begin{tabular}{lccc}
\hline Group & Measured value $(\mathrm{kN})$ & Theory value $(\mathrm{kN})$ & Relative error $(\%)$ \\
\hline S1 & 2.20 & 2.24 & 2.00 \\
S2 & 2.60 & 2.57 & -1.15 \\
S3 & 2.80 & 2.80 & 0.00 \\
S4 & 3.20 & 3.22 & 0.63 \\
S5 & 3.60 & 3.61 & 0.28 \\
\hline
\end{tabular}

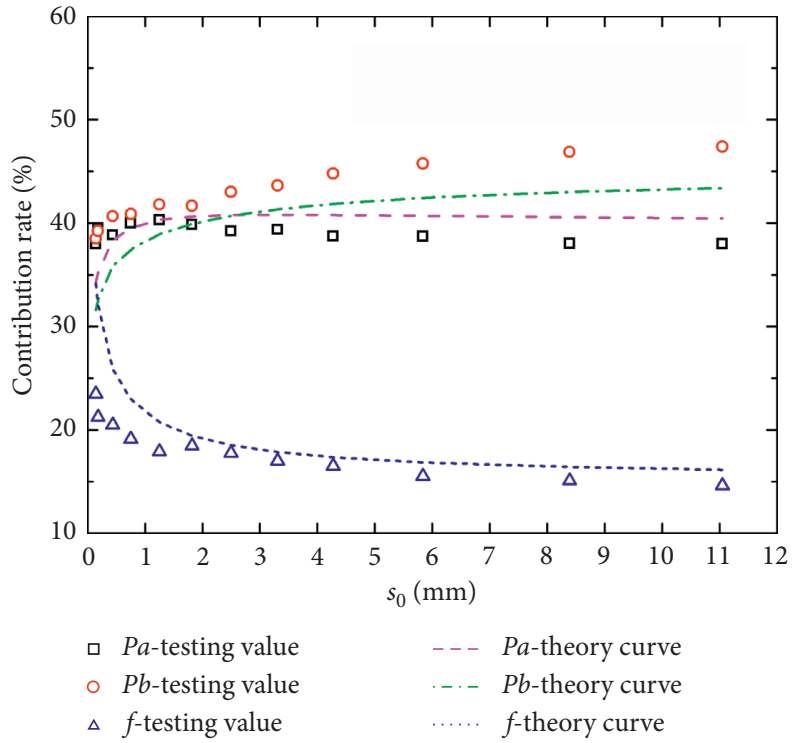

(a)

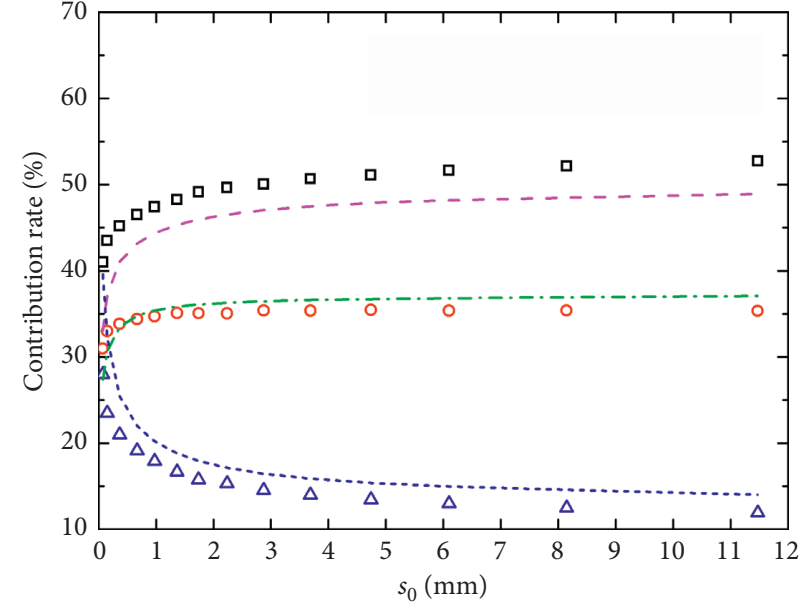
$P a$-testing value
- $P b$-testing value
- - $\quad P a$-theory curve
-.. $P b$-theory curve
$\Delta f$-testing value

(b)

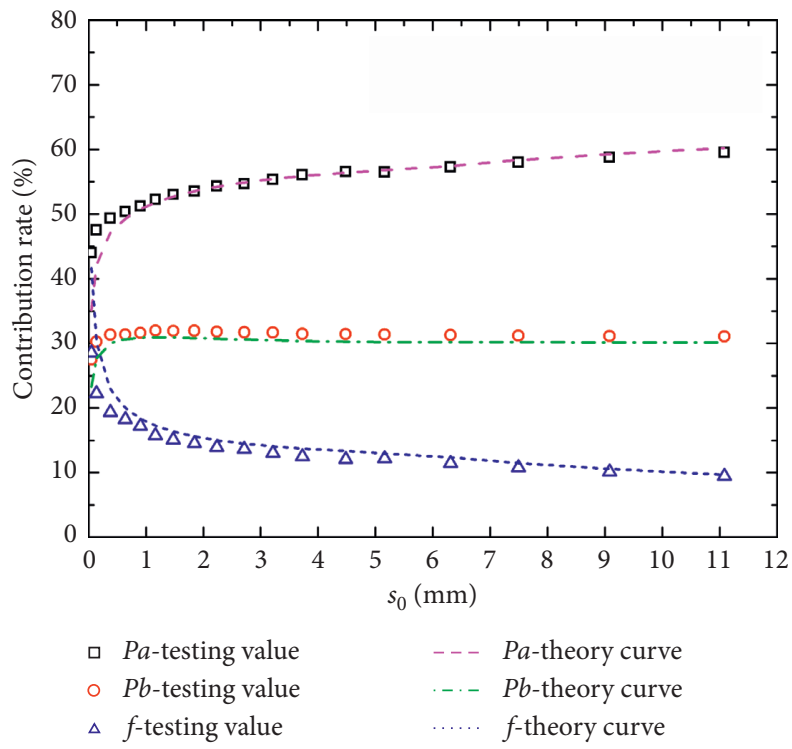

(c)

Figure 10: The comparison of the bearing capacity contribution: (a) S1, (b) S2, and (c) S3. 


\section{Conclusions}

(1) The calculation theory of pile bearing capacity based on the shear displacement method is established. According to the hyperbolic function relation, the load-settlement relation of pile tip resistance, pile skin resistance, and branch resistance is deduced, reflecting the nonlinear relation between pile and soil, and the theoretical model of the bearing capacity calculation of the single pile of the squeezed branch pile is established.

(2) Theoretical calculation methods of the load transfer function at the pile tip, pile skin, and branch were given. Theoretical calculation and comparative analysis were combined with the results of the laboratory model test, and the rationality of theoretical calculation was verified.

(3) The theory of pile bearing capacity has been verified in the homogenized soil model test. The results show that the squeezed branch single pile based on the shear displacement method can reliably predict the ultimate load of the actual project and provide good theoretical support for the design of bearing capacity.

\section{Data Availability}

The data used to support the finding of this study are available from the corresponding author upon request.

\section{Conflicts of Interest}

The authors declare that they have no conflicts of interest.

\section{Acknowledgments}

The authors sincerely thank the School of Civil Engineering and Architecture, State Key Laboratory of Mining Response and Disaster Prevention and Control in Deep Coal Mines, Anhui University of Science and Technology for providing the experimental conditions. This work was supported by the National Natural Science Foundation of China (51408006) and Guangxi Key Laboratory of Geomechanics and Geotechnical Engineering.

\section{References}

[1] L. Z. Yin, X. G. Fan, and S. J. Wang, "A study on application of squeezed branch pile in clay soil foundation," Earth and Environmental Science, vol. 61, no. 1, pp. 1-6, 2017.

[2] Q. Xiao, D. H. Wang, and J. Xu, "Experimental study on mechanical characteristics of squeezed branch piles for power transmission lines," Journal of ExperimentalMechanics, vol. 30, no. 1, pp. 124-130, 2015.

[3] G. L. Yang, S. H. Chen, and Y. L. Lin, "Contrastive experimental study between expanded diameter piles and equal diameter piles," Journal of Railway Science and Engineering, vol. 6, no. 2, pp. 34-42, 2009.
[4] F. Li, H. B. Song, and Y. D. Zhou, "Bearing characteristics of squeezed branch pile," Journal of Hohai University, vol. 38, no. 2, pp. 202-205, 2010.

[5] L. P. Zhang and X. M. Wang, "Comparisononload-bearing character is ticsamong equal diameter pile, branched pile and branch pile," Journal of Chang'an University, vol. 36, no. 5, pp. 37-44, 2016.

[6] W. Cui and Z. J. Wang, "Field experiment study on the bearing characteristics of squeezed branch pile in loess area," Applied Mechanics and Materials, vol. 166-169, pp. 13291332, 2012.

[7] Y. Zhang, P. Chen, and Z. X. Zhao, "Experimental study on squeezed branch pile foundation in soft soil ground," Chinese Journal of Geotechnical Engineering, vol. 35, no. S2, pp. 994-997, 2013.

[8] X. B. Liu, L. H. Chen, Z. Y. Yu, J. X. Hu, and W. Peng, "Experimental study on DX pile performance in frozen soils under lateral loading," Sciences in Cold and Arid Regions, vol. 5, no. 5, pp. 608-613, 2013.

[9] Y. Liang, S. F. Ren, D. X. Geng, and X. ShangGuan, "Research on vertical bearing capacity and settlement algorithm of large diameter and variable cross section Piles," Journal of East China Jiaotong University, vol. 26, no. 4, pp. 34-38, 2009.

[10] Y. H. Wu, G. Zheng, and S. W. Yan, "A settlement prediction method for multi-under-reamed cast-in-situ pile foundation," Chinese Journal of Geotechnical Engineering, vol. 5, pp. 528531, 2000.

[11] Y. W. Ju, R. W. Liang, X. H. Bai, and S. Y. Zhang, "Experimental study of bearing and deformation behavior of squeezed branch pile and its bearing capacity calculation," Engineering Mechanics, vol. 6, pp. 34-38, 2003.

[12] X. J. Gao and X. R. Zhu, "Forecasting ultimate bearing capacity of single squeezed branch pile by hyperbola method," Rock and Soil Mechanics, vol. 9, pp. 1596-1600, 2006.

[13] J. P. Jiang, G. Y. Gao, and B. H. Gu, "Bearing behaviors and description of Q-s curves of piles with expanded diameter based on power-hyperbola combined model," Engineering Mechanics, vol. 27, no. 11, pp. 120-126, 2010.

[14] G. B. Liu, G. J. Hu, Z. Han, Y. D. Zheng, and R. Y. Zheng, "Model tests on bearing behaviors and calculation of multistage expanded piles," Chinese Journal of Geotechnical Engineering, vol. 41, no. S2, pp. 149-152, 2019.

[15] L. X. Li, X. J. Li, and B. Liu, "A simplified nonlinear settlement analysis method for axial loaded squeezed and branch piles," Chinese Journal of Underground Space and Engineering, vol. 14, no. 4, pp. 904-911, 2018.

[16] M. F. Randolph and C. P. Wroth, "Analysis of deformation of vertically loaded piles," Journal of the Geotechnical Engineering Division, vol. 104, no. 12, pp. 1465-1488, 1978.

[17] H. B. Seed and L. C. Reese, "The action of soft clay along friction piles," in Proceedings of the American Society of Civil Engineers, pp. 731-754, St. Louis, MO, USA, 1955.

[18] M. F. Randolph and C. P. Wroth, "An analysis of the vertical deformation of pile groups," Géotechnique, vol. 29, no. 4, pp. 423-439, 1979.

[19] N. Janbu, "Static bearing capacity of friction piles," in Proceedings of the European Conference on Soil Mechanics and Foundation Engineering, pp. 479-488, Vienna, Austria, March 1976.

[20] F. H. Kulhawy, "Limiting tip and side resistance: fact or fallacy?" in Proceedings of the Symposium on Analysis and Design of Pile Foundations, San Francisco, CA, USA, October 1984. 
[21] J. Yang, L. G. Tham, P. K. K. Lee, S. T. Chan, and F. Yu, "Behaviour of jacked and driven piles in sandy soil," Géotechnique, vol. 56, no. 4, pp. 245-259, 2006.

[22] S. T. Tang, Research on bearing mechanism and settlement of single DX pile and DX pile group, Ph.D. thesis, Beijing Jiaotong University, Beijing, China, 2012, in Chinese. 